\title{
MINERAL DUST IN CENTRAL ASIA: COMBINING LIDAR AND OTHER MEASUREMENTS DURING THE CENTRAL ASIAN DUST EXPERIMENT (CADEX)
}

\author{
Dietrich Althausen $^{1, *}$, Julian Hofer ${ }^{1}$, Sabur Abdullaev ${ }^{2}$, Abduvosit Makhmudov ${ }^{2}$, Holger \\ Baars $^{1}$, Ronny Engelmann ${ }^{1}$, Khanneh Wadinga Fomba ${ }^{1}$, Konrad Müller ${ }^{1}$, Georg \\ Schettler $^{3}$, Lars Klüser ${ }^{4}$ and Konrad Kandler ${ }^{5}$ \\ ${ }^{1}$ Leibniz Institute for Tropospheric Research, Germany, *dietrich@tropos.de \\ ${ }^{2}$ Physical Technical Institute of the Academy of Sciences of Tajikistan, Tajikistan \\ ${ }^{3}$ GFZ German Research Centre for Geosciences, Germany \\ ${ }^{4}$ German Aerospace Center (DLR), German Remote Sensing Data Center, Germany \\ ${ }^{5}$ Technical University Darmstadt, Germany
}

\begin{abstract}
Mineral dust needs to be characterized comprehensively since it contributes to the climate change in Tajikistan / Central Asia. Lidar results from the measurements of mineral dust during CADEX are compared with results of sun photometer measurements, satellite-based measurements, and chemical analysis of ground samples. Although the dust is often advected from far-range sources, it impacts on the local conditions considerably.
\end{abstract}

\section{INTRODUCTION}

Central Asia is part of the desert (or dust) belt from the Sahara, over the Saudia Arabian and Iranian deserts, to the East-Asian deserts like the Gobi desert. Within this belt, often mineral dust is lifted up into the atmosphere and advected thousands of kilometers to other locations as for instance to Tajikistan / Central Asia. Such dust events contribute significantly to the climate change in Central Asia.

Chemical measurements at the ground, vertically-resolved lidar measurements, and satellite-based measurements complement each other since the first are much more comprehensively regarding the constituents of the atmospheric particles, while the second relate the atmospheric vertical layers to each other, while the third provide a horizontal prospective. The task of this contribution is to illustrate simultaneous outputs of these three types of mineral dust measurements at Dushanbe.

\section{CENTRAL ASIAN DUST EXPERI- MENT (CADEX)}

Long-lasting vertically resolved aerosol measurements were not available in Tajikistan so far. To fill this gap of knowledge, the Central Asian DUst EXperiment (CADEX) took place at Dushanbe, the capital of Tajikistan, from March 2015 until August 2016. The measurement site was located at the latitude of $38^{\circ} 33^{\prime} 34^{\prime \prime} \mathrm{N}$ and the longitude of $68^{\circ} 51^{\prime} 22$ "E, and at the elevation of $864 \mathrm{~m}$ a.s.l. on a small hill some hundred meters away from a big road. Within this experiment combined multiwavelengths Raman and polarization lidar and sun photometer measurement were performed to assess the aerosol loading over Dushanbe. Chemical measurements accompanied these measurements to get insights to the chemical constituents of the particles at ground level. Further details to CADEX can be found in $[1,2]$ and at http://www.tropos.de/en/research/ 


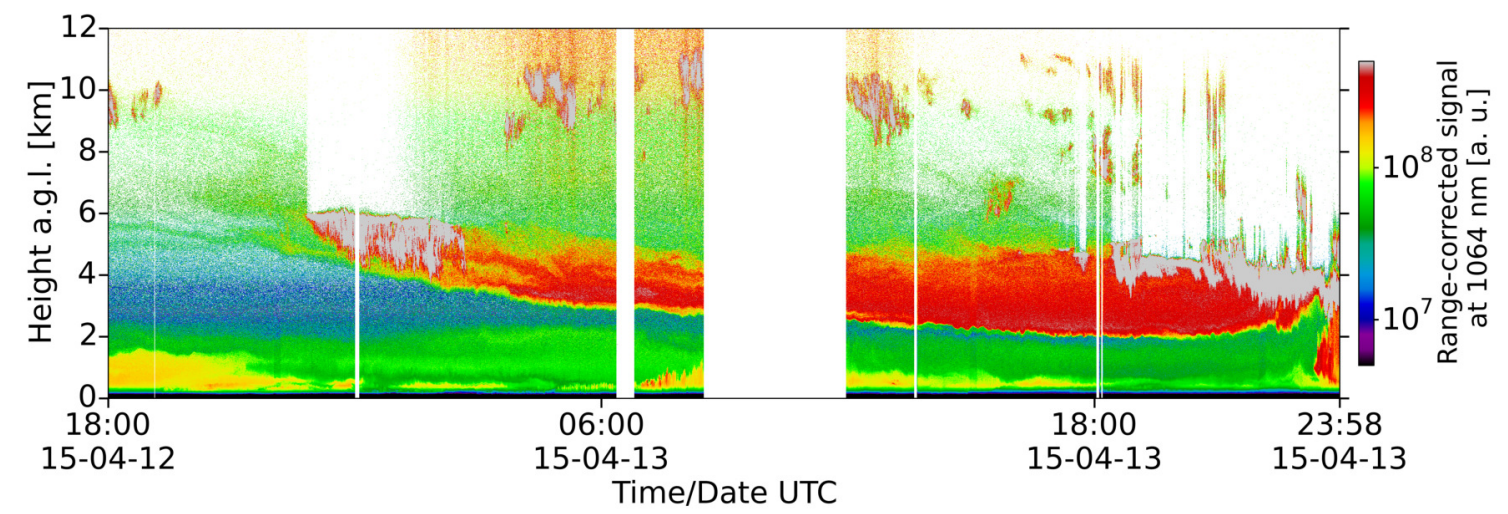

Figure 1: Temporal development of the range-corrected signal at $1064 \mathrm{~nm}$ wavelength between 12 April 2015, 18:00 UTC and 13 April 2015, 23:58 UTC.

projects-infrastructures-technology/ research-projects/cadex/.

\section{LIDAR, IASI, AND CHEMICAL MEA- SUREMENTS}

The deployed multiwavelength Raman and polarization $(3+2+2)$ lidar is a Polly $\mathrm{XT}$ from TROPOS [3]. This system is part of the Polly ${ }^{\text {NET }}$ [4] and its quicklooks are accessible via http://polly.tropos.de. An example of a lidar measurement at Dushanbe is shown in Fig. 1. This measurement shows an optically thick lofted dust layer that is decoupled from ground at the beginning and is mixed down at the end of the measurement time. Examples of more profiles are shown in [2]. Other examples are presented in $[1,2]$. The identification of aerosol layers containing dust in section 4 is done by using the linear particle depolarization ratio. $10 \%$ was set as the minimum value for a dust containing layer. Using this condition, the lower and upper limits of the layers are determined by the maximum gradients of the particle backscatter coefficient profile.

The used sun photometer is made by the company CIMEL and is part of AERONET. Its data (for instance the aerosol optical thickness; AOT) are accessible via http://aeronet.gsfc.nasa.gov/

cgi-bin/type_one_station_opera_v2_ new? site=Dushanbe\&nachal=2\&level=1.

The Infrared Mineral Aerosol Retrieval Scheme (IMARS) is applied to hyperspectral infrared observations of the Infrared Atmospheric Sounding Interferometer (IASI) on board of the polar orbiting Metop-A satellite (equator crossing time 10:30 LST) in order to retrieve desert dust aerosol optical depth, emission temperature (and thus layer height) and other parameters. A description of the method and its capabilities in full detail can be found in [5, 6].

The collection of PM10 aerosol was carried out on quartz fiber filters (MK 360, MUNKTELL) using a high-volume filter sampler (DHA-80, DIGITEL). These samplings were taken over 48 hours (sampling volume about $1520 \mathrm{~m}^{3}$ ) during CADEX. Weighing of filters and all chemical analysis were carried out at TROPOS laboratories according to the techniques described in [7]. 
4 COMBINATION OF MEASUREMENTS AT GROUND, VERTICALRESOLVED, AND SPACE-BASED MEASUREMENTS

Figure 2 summarizes the results from the different measurements for April 2015. Parts a), b), and c) of Fig. 2 show results of the sun photometer, the lidar, and the IASI measurements, but only if lidar and IASI measurements were possible.

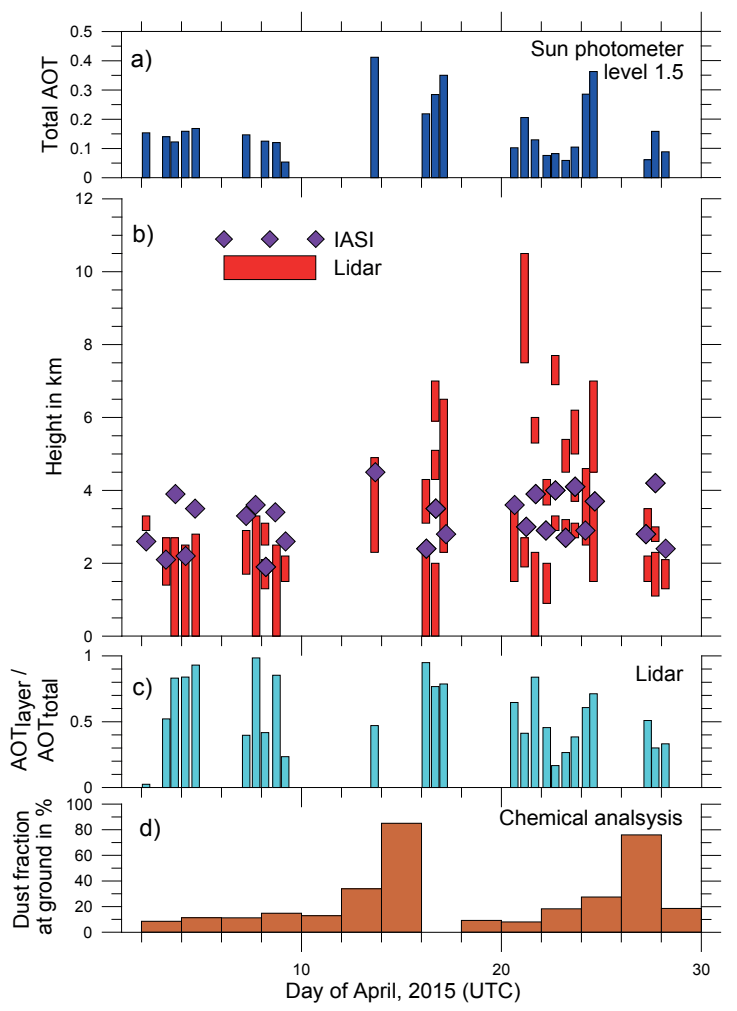

Figure 2: Results from 2 to 30 April 2015. A), b), and c) show only results if lidar AND IASI data are available. a) Aerosol optical thickness (AOT) at $500 \mathrm{~nm}$ measured with the sun photometer. b) Dust containing layer heights (red) from lidar measurements. Dust altitude (DALT) from IASI in violet. c) Ratio of aerosol optical thickness of the dust containing layers to the total aerosol optical thickness (from lidar). d) Dust fraction of particles determined by chemical measurements.
The measurements of April 2015 indicate periods with different dust conditions:

- 2 - 9 April: low dust layers, small dust fraction in chemical samples, 6 times: DALT values from IASI $>$ maximum layer heights from lidar, 4 times: DALT values from IASI < maximum layer heights from lidar;

- 9 - 13 April: no IASI measurements, small and moderate dust fraction in chemical samples;

- 13 April: lofted dust layer, large AOT, moderate dust fraction in chemical sample, DALT from IASI < maximum layer height from lidar, down-mixing of dust (compare Fig. 1);

- 14 - 15 April: clouds, rain, very large dust fraction in chemical sample;

- 16 - 17 April: low and lofted dust layers, high dust load (large AOT; large fraction of AOT from layers), DALT values from IASI < maximum layer heights from lidar;

- 17 - 20 April: rainy, low-level clouds, no combined measurements of lidar and IASI;

- 20 - 24 April: often lofted dust layers, moderate dust load and partly large fraction of AOT from layers, DALT values from IASI < maximum layer heights from lidar, at the end of this period large AOT in lofted layers;

- 25 - 26 April: rain and no lidar measurements, very large dust fraction in chemical sample;

- 27 - 28 April: lofted dust layers, low to moderate dust load (AOT), 2 times DALT values from IASI $>$ maximum layer heights from lidar, 1 time: DALT values 
from IASI < maximum layer heights from lidar;

- 28 - 30 April: no lidar measurements.

\section{DISCUSSION}

CADEX provides a unique data set about the aerosol in Central Asia. This contribution describes measurements of April 2015 done with an aerosol lidar, a sun photometer, the spacebased IASI, and chemical analysis. Often lofted layers were advected over Tajikistan. 2 periods had been observed with first lofted aerosol layers, then down mixing of dust, rain, and subsequent high dust fractions in the particles at ground. The dust altitudes from IASI were in the range between 1.9 and $4.5 \mathrm{~km}$ height, while the lidar-observed heights ranged from ground to $10.5 \mathrm{~km}$ height.

\section{ACKNOWLEDGEMENTS}

The CADEX project was funded by the German Federal Ministry of Education and Research in the context of "Partnerships for sustainable problem solving in emerging and developing countries" under the grant number 01DK14014. This project has also received funding from the European Union's Horizon 2020 research and innovation programme under grant agreement No 654109.

\section{References}

[1] Hofer, J., D. Althausen, et. al., 2017: Mineral Dust in Central Asia: 18-Month Lidar Measurements in Tajikistan during the Central Asian Dust EXperiment (CADEX), this conference.

[2] Hofer, J., D. Althausen, et al., 2016: Central Asian Dust Experiment (CADEX): Multiwavelength Polarization Raman Lidar Observations in Tajikistan, EPJ Web of Con- ferences, 119, 18006, doi:dx.doi.org/10. 1051/epjconf/201611918006

[3] Engelmann, R., T. Kanitz, et al., 2016: The automated multiwavelength Raman polarization and water-vapor lidar Polly ${ }^{\mathrm{XT}}$ : the neXT generation, Atmos. Meas. Tech., 9, 1767-1784, doi:dx.doi.org/10.5194/ amt-9-1767-2016.

[4] Baars, H., T. Kanitz, et al., 2016: An overview of the first decade of Polly NET: an emerging network of automated Raman-polarization lidars for continuous aerosol profiling, Atmos. Chem. Phys., 8, 5111-5137, doi:dx. doi.org/10.5194/acp-16-5111-2016.

[5] Klüser, L., J.R. Banks, et al. 2015: Information content of space-borne hyperspectral infrared observations with respect to mineral dust properties, Remote Sensing of Environment, 156, 204-309, doi:dx.doi.org/10. 1016/j.rse.2014.09.036.

[6] Klüser, L., C. Di Biagio, et al., 2016: Optical properties of non-spherical desert dust particles in the terrestrial infrared - An asymptotic approximation approach, J. Quant. Spectrosc. Radiative Transf., 178, 209-223, doi:dx.doi . org/10.1016/j.jqsrt. 2015.11.020.

[7] Fomba, K. W., Müller, K., et al. 2014: Long-term chemical characterization of tropical and marine aerosols at the Cape Verde Atmospheric Observatory (CVAO) from 2007 to 2011, Atmos. Chem. Phys., 14, 8883-8904, doi:dx.doi.org/10.5194/ acp-14-8883-2014. 